\title{
Mapping climate change adaptive capacity and vulnerability of smallholder agricultural livelihoods in Central America: ranking and descriptive approaches to support adaptation strategies
}

\author{
Claudia Bouroncle ${ }^{1}$ (D) Pablo Imbach ${ }^{1}$. \\ Beatriz Rodríguez-Sánchez ${ }^{2}$ - Claudia Medellín ${ }^{1}$. \\ Armando Martinez-Valle ${ }^{2}$ Peter Läderach ${ }^{2}$
}

Received: 12 November 2015 / Accepted: 26 August 2016/Published online: 28 September 2016

(C) The Author(s) 2016. This article is published with open access at Springerlink.com

\begin{abstract}
Climate change is one of the main threats to rural livelihoods in Central America, especially for small and medium-sized farmers. Climate change vulnerability assessment (CCVA) integrates biophysical and socioeconomic information to support policy decisions. We present a CCVA of agricultural livelihoods of four countries in Central America, at the municipality level. We use the IPCC definition of vulnerability, and address the potential impact of climate change on suitability for major crops and adaptive capacity using indicators of basic human needs, as well as resources for innovation and action framed in a livelihoods approach. Adaptive capacity was estimated using ranking techniques for municipalities and descriptive multivariate analysis. Projected changes in climate suitability for crops show a wide variation between Guatemala, El Salvador, Honduras and Nicaragua, and within each country. Cluster analysis of adaptive capacity values shows a gradient between higher values close to urban areas and lower values in agricultural frontier areas and in those prone to drought. Municipalities with a high proportional area under subsistence crops tend to have less resources to promote innovation and action for adaptation. Our results suggest that a full spectrum of adaptation levels and strategies must be considered in the region to achieve
\end{abstract}

This article is part of a Special Issue on "Climate change impacts on ecosystems, agriculture and smallholder farmers in Central America" edited by Camila I. Donatti and Lee Hannah.

Electronic supplementary material The online version of this article (doi:10.1007/s10584-016-1792-0) contains supplementary material, which is available to authorized users.

Claudia Bouroncle

cbouron@catie.ac.cr

1 Climate Change Program, Tropical Agricultural Research and Higher Education Center (CATIE), CATIE 7170 Apartado 56, Turrialba 30501 Cartago, Costa Rica

2 Decision and Policy Analysis Research Area (DAPA), International Centre for Tropical Agriculture (CIAT), Cali, Colombia 
different adaptation goals. They also show that the adaptive capacity ranking and characterization are complementary and support geographical prioritization and identification of adaptation strategies, respectively.

\section{Introduction}

Central America is the tropical region where the biggest changes in future climate are expected (Giorgi 2006). It is expected to become drier resulting from reduced precipitation and increased temperatures (Imbach et al. 2012) as well as to have stronger dry seasons (Rauscher et al. 2008), the factor that driver the agriculture calendar. The region is recursively affected by droughts, cyclones and the El Niño-Southern-Oscillation (Bárcena et al. 2011). Between 1960 and 2000, it experienced increases in temperature and although significant changes have not been observed in total annual precipitation, an increased proportion of precipitation has been observed during extreme events (Aguilar et al. 2005). The global climate risk index (Harmeling and Eckstein 2012) shows that between 1992 and 2011 Honduras was the world's most vulnerable country to extreme weather events, Nicaragua the 3rd most vulnerable, Guatemala the 11th, and El Salvador the 15th; Costa Rica and Panama, the southernmost countries of the region, are much less exposed to extreme weather events and less vulnerable according to this index (72nd and 108th respectively). Imbach et al. (2016, this issue) provide a more detailed description of the region's climatic trends and projected future changes.

Agriculture, still a pillar for rural economies and for the food security of the poorest sectors of Central American society (Tucker et al. 2010), is one of the region's most vulnerable sectors to climate variability (CCAD 2010). Despite favourable socio-economic changes in recent decades, inequality and rural poverty still persist across countries (Corbacho and Davoodi 2002; Siegel 2005). UNDP (2014) classifies El Salvador, Guatemala, Honduras and Nicaragua as Medium Human Development countries, while Panama and Costa Rica are classified as High Human Development countries with less agriculture-dependent economies.

Lower crop productivity in the region is related to low population density, rainfall seasonality and low soil fertility (Kok and Veldkamp 2001). The Pacific watershed has more pronounced rain seasonality and has been more densely populated due to better agroecological conditions (Finegan and Bouroncle 2008). The Central American Dry Corridor comprises the driest, most seasonal part of this area and runs from Guatemala to Costa Rica. National statistics show that subsistence crops, like maize and other basic grains, are located predominantly in areas with lower population density. Agro-industrial crops like sugarcane predominate in areas with higher population density and in coastal areas, and coffee predominates on volcanic soils at intermediate altitudes.

To promote proactive adaptation in agriculture, policy makers need to know who are most vulnerable, what stresses they face, and what resources are available for adaptation (Ford et al. 2010). Climate change vulnerability assessments (CCVA) are commonly used to define and prioritize climate change adaptation interventions (Metternicht et al. 2014; Tonmoy et al. 2014). Studies across Central America have shown the potential impacts (PI) of climate change on coffee (Bunn et al. 2015; Ovalle-Rivera et al. 2015), maize (Gourdji et al. 2015; Schmidt et al. 2012), and beans (Schmidt et al. 2012) at the country level, and assessed the vulnerability of coffee smallholders (Rahn et al. 2014; Baca et al. 2014) and groups of communities that depend on maize and beans cultivation (Schmidt et al. 2012). However, 
the PI studies focus on selected crops (especially coffee) and the climate change vulnerability assessments focus on farmer groups (e.g. coffee cooperative members or farmers with organic certification), and most of them present results only for certain areas within countries. A truly regional assessment integrating the range of crops important to smallholders is therefore still lacking. To our knowledge, existing regional (SICA 2008; CCAD 2010) and national strategies (MAGA 2012; MAG 2012; SAG 2010; MAGFOR 2013) for adaptation of the agricultural sector and dependent rural livelihoods in Central America lack a definition of geographical priorities (where to adapt) and type of adaptation measures (how to adapt). Regional-scale CCVA captures key gradients of biophysical and socio-economic factors (Tonmoy et al. 2014). Approaches based on indicators and visualization techniques, and that use available information, are cost-effective and transparent frameworks for comparative analysis, and help to understand context-specific aspects of vulnerability and to identify actions (Malone and Engle 2011).

To contribute to the identification of adaptation priorities of smallholder agricultural livelihoods in Central America, we quantify climate change vulnerability at the municipality level across four countries with the lowest human development in the region, according to UNDP, using sector wide census data and crop suitability modelling. We also present a ranking approach and a multivariate statistical analysis to determine the geographic distribution of adaptive capacity (AC) of rural populations, identify and describe groups of municipalities with similar AC (e.g. Sietz et al. 2011, 2012) and discuss the implications of our results for adaptation planning.

\section{Data and methods}

\subsection{Vulnerability assessment assumptions}

We developed a quantitative indicator-based CCVA of rural agricultural livelihoods and applied it at the municipality level in Guatemala, El Salvador, Honduras and Nicaragua. Municipality, as defined by national constitutions in these countries, is the second level of administrative division and is also the basis of their territorial, political and administrative organisation. The first level of administrative division (departments) was too large for the purposes of this study.

We defined rural agricultural livelihoods as the combination of cash and subsistence crops for small- and medium-scale farmers in each municipality. Crops included were coffee, maize, beans, upland rice, sorghum, plantain, and cassava. Each of these crops accounts for more than $0.5 \%$, on average, of the cultivated area in the four countries (excluding pastures) (Supplementary Material 1) according to the latest agricultural census or statistics for each country (Supplementary Material 2). We considered 1019 municipalities in our analysis and excluded those lacking rural population (18), census data (1) or out of the current and projected environmental ranges of all their current crops (6).

We define vulnerability as expected change in agricultural livelihoods over a given timeframe, as a function of exposure, sensitivity and AC (Parry et al. 2007). Exposure is defined as the degree and direction of change of climate variables, sensitivity as the characteristics that determine how a system is affected by these changes, and $\mathrm{AC}$ as the ability of a system to adjust to these changes. The combination of exposure and sensitivity define the potential impact (PI) that may occur given a projected change in climate, without considering adaptation (Locatelli et al. 2008). 


\subsection{Potential impact (crop modelling)}

PI was represented for each municipality as the expected absolute change in climatic suitability for crops in it, weighted by the proportional area of each crop (the area occupied by a given crop divided by the total area occupied by all crops). We quantified current exposure for the 1960-2000 period using 19 bioclimatic variables available in WorldClim (Hijmans et al. 2005). Future exposure was derived from 24 General Circulation Models from the IPCC Fourth Assessment Report for the 2020-2049 (2030s) period and A1B mid-emission scenario, using the downscaling procedure of Ramírez-Villegas and Jarvis (2010). We used the EcoCrop mechanistic model (Hijmans et al. 2001) to quantify current and future suitability ranges for each crop. Variables used to calculate current and future suitability and to parameterize EcoCrop were defined by previous research and expert judgment, including that of crop specialists (Supplementary Material 3). We obtained the proportional suitability change for each crop as the difference between the projected and current potential suitability values in each pixel. For each municipality we determined the mean suitability change for each crop and a Weighted Average Suitability Change (WASC), as the mean suitability change for each crop weighted by the fraction of total agricultural area occupied by that crop.

\subsection{Adaptive capacity and vulnerability ranking}

We mapped the Adaptive Capacity Index (ACI) of the rural population in the municipalities as a function of three conditions selected by us in relation to human, natural, built, and financial capitals (Scoones 2009; Flora et al. 2015): basic needs satisfaction, resources for innovation and resources for transforming innovation into actions. We developed criteria to characterize each condition based on the livelihoods approach recommended for CCVA of rural smallholder farmers (Knutsson and Ostwald 2006; Eakin and Bojórquez-Tapia 2008; Imbach and Prado 2013). We based the selected indicators for each criteria (see Table 1) on literature specific to Central America (Corral and Reardon 2001; Lanjouw 2001; Ruben and Van Den Berg 2001). The same indicators and calculations (Supplementary Material 4) were applied in all municipalities, so indicator selection was constrained by available spatial information covering all countries from the latest population and housing censuses and public health statistics (Supplementary Material 2). We normalized indicator values linearly to a $0-1$ interval based on their minimum and maximum values in each country, to avoid biases regarding differences in socioeconomic development between countries. We used the inverse values of some indicators, so that increases in values always represent increases in AC.

We assumed equal weights for the three ACI conditions as they represent successive steps in an innovation process (Imbach and Prado 2013), based on basic needs satisfaction (the Maslow perspective applied to human development, see Hagerty 1999) and motivation and information as the basis for a transition from reactive to planned responses (Flora 2004). Criteria weights (Table 1) were based on a survey completed by 33 regional experts (from 44 approached) from Central American public agencies, universities, research and development organizations, global agriculture and climate change research organisations, and multilateral agencies (Supplementary Material 5). The experts were selected by the CGIAR Research Program on Climate Change, Agriculture and Food Security (CCAFS) and their respective organisations to participate in a workshop in 2013 to define regional priorities for this program. We asked the experts to rank criteria and assessed the mode of the resulting values for each criterion using the ranking sum method (Stillwell et al. 1981) to generate numerical weights, as 


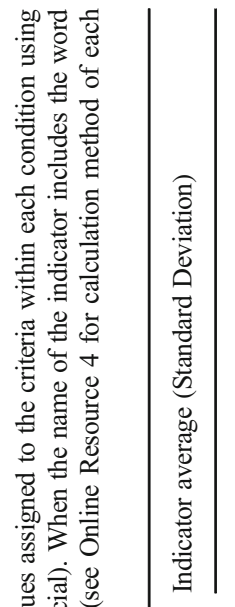

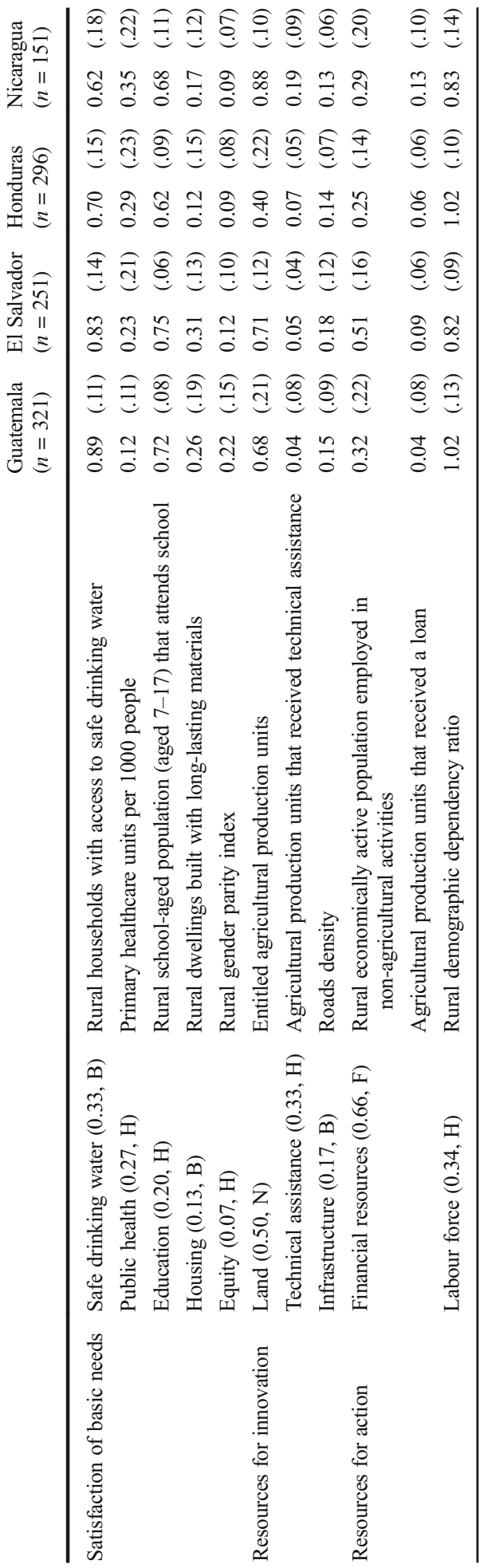


recommended by Malczewski (1999) for small sets of parameters. We evaluated most criteria through one indicator, when two were available used the average as the criterion value.

Finally, we calculated a Vulnerability Index (VI) for each municipality as the sum of PI and ACI, and the values obtained were normalized linearly to a $0-1$ interval, again based on their minimum and maximum values in each country; we used these values to classify municipalities into three quantiles representing lower, intermediate and higher vulnerability. We also calculated an index by weighting indicators using the principal component analysis (PCA) eigenvector values (section 2.4). We performed calculations separately for each country.

\subsection{Adaptive capacity clusters}

Cluster analysis has been used in previous CCVA (Sietz et al. 2011, 2012) to reveal vulnerability patterns that show typical combinations of the units of analysis based on their attributes. In this study, we grouped municipalities with similar AC patterns in each country separately using cluster analysis with Euclidean distance and Ward's algorithm. We selected the minimum number of clusters that showed (i) the greatest decline of the k-means algorithm and (ii) tolerance to misclassification $<20 \%$, using the apparent error rate obtained from discriminant analysis. We used multivariate analysis of variance (MANOVA) to determine whether indicator values differed significantly between clusters and inferred the main determinants of AC using PCA. We compared AC clusters using the mean values of individual indicators for each weighted by the eigenvectors from the first PCA component. Finally, we compared mean cluster values of AC indicators, other social indicators not directly related to AC and the proportion of area occupied by different crops, using analysis of variance (ANOVA) and Tukey's test. All statistical analysis was done using InfoStat 2015 (Di Rienzo et al. 2015).

\section{Results}

\subsection{Potential impact of climate change on crops}

Almost half the municipalities (514) will lose some climatic suitability to sustain their current cash and subsistence crop combinations (WASC between $-0.1 \%$ and $-31 \%$ ). The rest (505) will gain suitability (WASC between $0.1 \%$ and $59 \%$ ). Around half (512) of the municipalities had a WASC of $10 \%$ or less (Supplementary Material 6). On average, El Salvador and Nicaragua are projected to experience a decline of WASC ( $-5 \%$ and $-6 \%$ respectively), but increases are projected for mountainous Honduras and Guatemala $(0.5 \%$ and $8 \%$ respectively). Coffee, beans and plantain are likely to suffer decreases in suitability across all countries, resulting from increased temperatures in low altitude areas. Maize (a C4 photosynthetic pathway crop), cassava, upland rice and sorghum (also $\mathrm{C} 4$ ) will gain climatic suitability in all countries (details in Supplementary Material 6 and 7) (Fig. 1).

\subsection{Adaptive capacity index and vulnerability ranking index}

ACI showed a gradient from higher values close to major urban areas and trade routes to lower values in municipalities prone to drought (Dry Corridor, mainly eastern Guatemala, western Honduras and northern and eastern El Salvador) or closer to areas where agriculture is expanding progressively at the expense of natural forests 

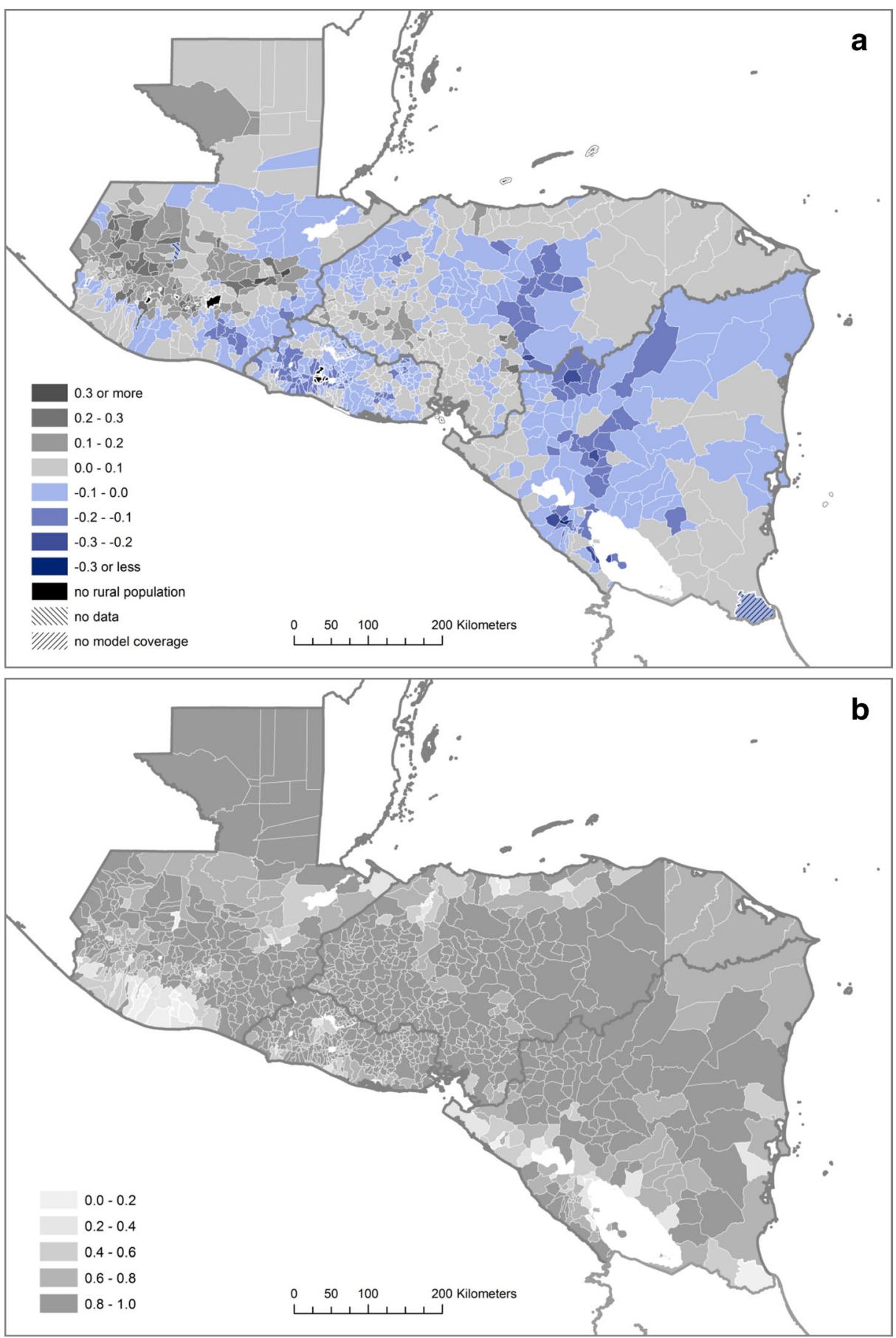

Fig. 1 a Average change in suitable areas for the current crop combination (coffee, beans, maize, upland rice, sorghum, plantain, and cassava, based on the most recent agricultural censuses) for 2030 in municipalities of Guatemala, El Salvador, Honduras and Nicaragua. b Proportion of agricultural area occupied by at least one of the crops considered in the study 


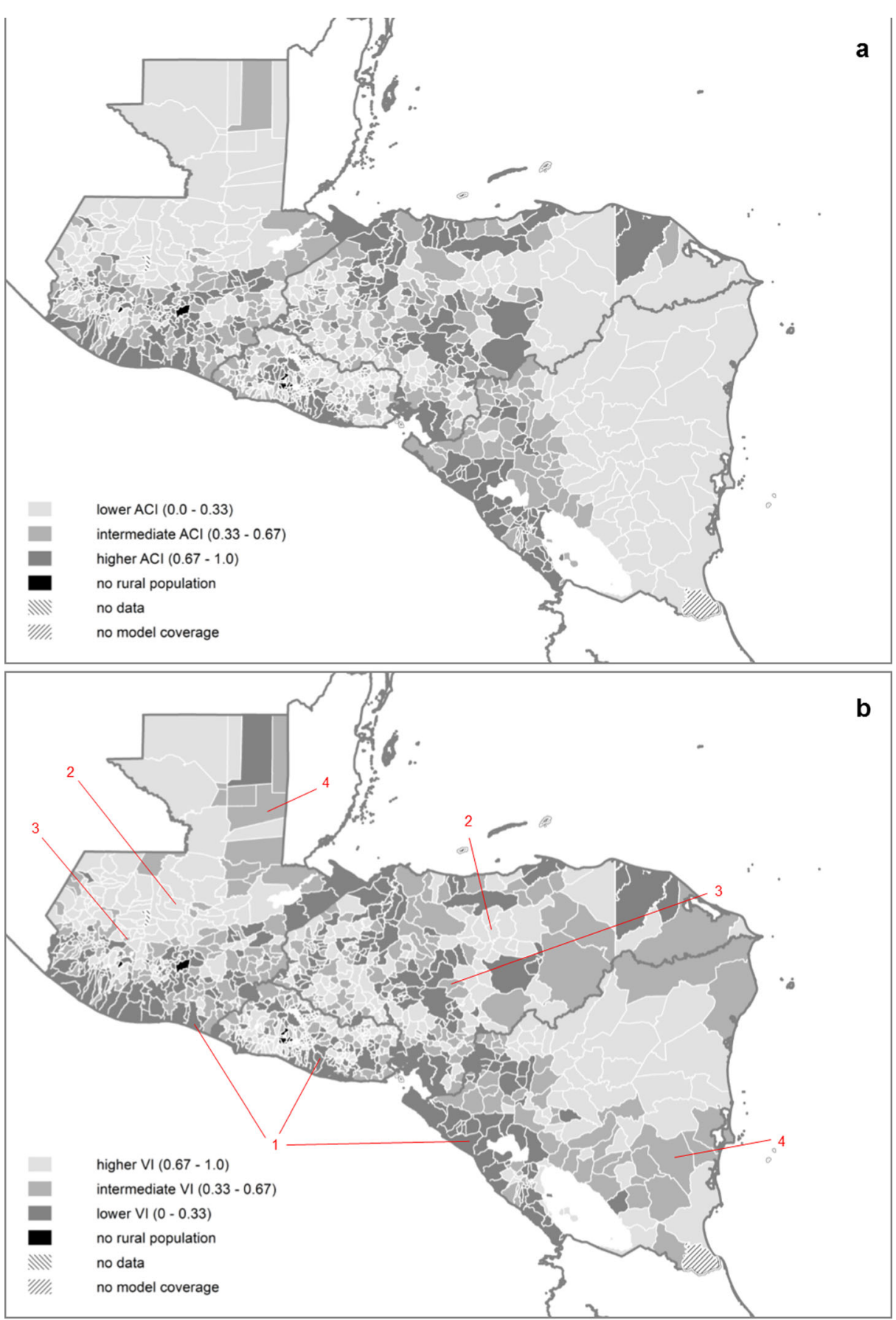

Fig. 2 Adaptive Capacity Index - ACI (a) and Vulnerability Index - VI (b) of municipalities determined by the ranking analysis. Numbers on (b) show cases referred to in the text 
(in northern Guatemala, north-eastern Honduras, and eastern Nicaragua) which is hereafter called "the agricultural frontier" (Fig. 2a).

Municipalities with lower PI and higher ACI are in the category of lowest VI. Examples are municipalities including or close to urban areas in the Pacific coast of Guatemala, El Salvador and Nicaragua, where combinations of maize, sorghum, and agro-industrial crops predominate (Fig. 2b, Case 1). Higher VI values include municipalities with higher PI due to high suitability changes (e.g. suitability gain for coffee and beans, Guatemala; or suitability loss for the same crops in Honduras, Fig. 2b, Case 2) and lower ACI. Municipalities with intermediate VI have higher ACI and lower PI or the inverse. Examples of the former are municipalities that contain or are close to major urban areas and face higher suitability change (e.g. suitability gain for beans, Guatemala; suitability loss for the same crop, Honduras, Fig. 2b, Case 3). Among the latter are municipalities in agricultural frontiers that will experience smaller changes in suitability (e.g. suitability gain for maize, Guatemala; suitability gain for upland rice and cassava, Nicaragua, Fig. 2b, Case 4).

\subsection{Adaptive capacity clusters}

The minimum number of clusters of municipalities is highest in Guatemala and El Salvador (7 clusters in each), intermediate in Honduras (6), and lowest in Nicaragua (5). MANOVA indicated significant differences $(p<0.001)$ between all clusters in each country. Apparent error rates in the allocation of municipalities to clusters, i.e. the probability that a municipality has been erroneously assigned to a cluster, ranged between 10 and $17 \%$ (Guatemala $15 \%$, El Salvador $17 \%$, Honduras $16 \%$, Nicaragua $10 \%$ ). The spatial distribution of clusters by AC level follows the same trend found for ACI (Fig. 3).

In most countries, the indicators with higher eigenvectors on the first component of the PCA (PC1, see PCA biplots in Supplementary Material 8 and eigenvector values in Supplementary Material 9) included those related to basic needs satisfaction and access to resources for innovation and action. That is, better performance inferred from these indicators (higher mean indicator values) was related to higher AC of the clusters. These basic needs satisfaction indicators include safe drinking water (in Honduras and Nicaragua), rural schoolaged population attending school (in all countries), rural dwellings built with long-lasting materials (in all countries) and the rural gender parity index (in all countries), those for access to resources for innovation and action include road density (in Guatemala, El Salvador, Nicaragua), rural economically active population with non-agricultural employment (in all countries), and rural demographic dependency ratio (in all countries). Some indicators nevertheless do not follow this pattern. Indicators with lower or negative eigenvector values on PC1 include those related to agricultural and health services. Better performance inferred from these indicators is related to clusters with intermediate or lower AC. These indicators include primary healthcare units per 1000 people (in El Salvador, Honduras, and Nicaragua) and the proportion of agricultural production units that receive technical assistance and/or an agricultural loan (in all countries). The proportion of entitled agricultural production units is highly negatively related with PC1 in Guatemala and Nicaragua and less so in El Salvador and Honduras.

In all countries, clusters with higher $\mathrm{AC}$ have higher population density and higher proportions of agricultural land under cash crops, while those with lower AC have a higher proportion of land under basic grains (all comparisons using ANOVA; see $p$ values in Supplementary Material 10). Clusters with higher proportions of agricultural production units receiving technical assistance and loans also have higher proportions of land under coffee, and 

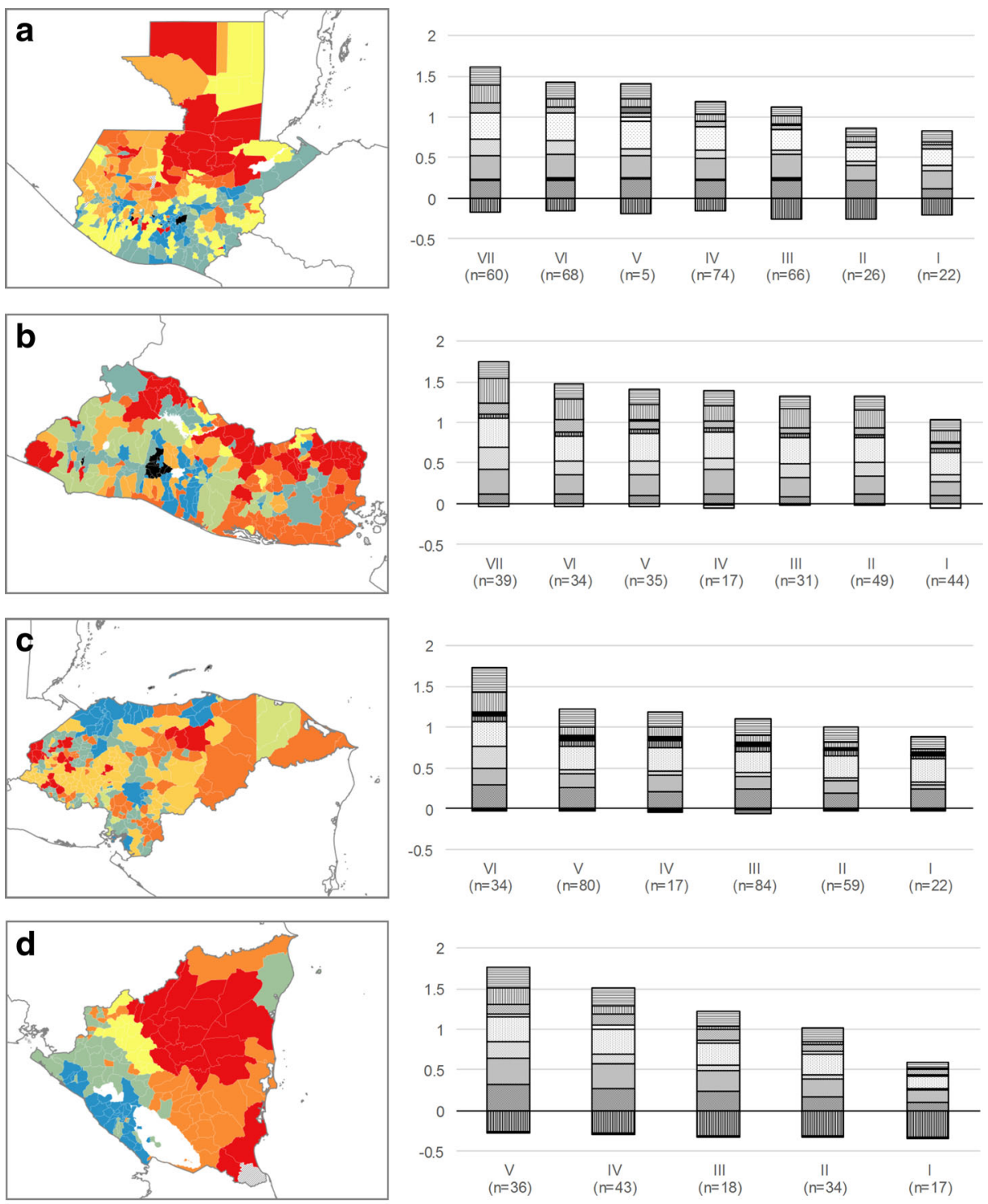

Adaptive capacity level

Indicators legend

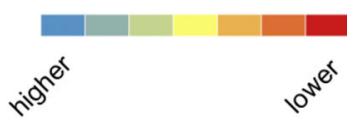

\begin{tabular}{|c|c|c|}
\hline 图 water & healthcare & roschool \\
\hline 圈housing & Dequity & m tenure \\
\hline 口assistance & roads & ㅁloans \\
\hline
\end{tabular}


Fig. 3 Adaptive capacity distribution based on the results of cluster analysis depicting the combination of indicators at the cluster centres. a Guatemala, b El Salvador, c Honduras, and d Nicaragua. Indicator values at the cluster centres are weighted by factor scores from the first component of a Principal Component Analysis. Adaptive capacity of municipality clusters decreases from left to right on the bar diagrams. water $=$ Rural households with access to safe drinking water; healthcare = Primary healthcare units per 1000 people; school = Rural school-aged population that attends school; housing = Rural dwellings built with long-lasting materials; equity $=$ Rural gender parity index, tenure = Entitled agricultural production units; assistance = Agricultural production units that received technical assistance; roads = Roads density; non agricultural EAP $=$ Rural economically active population employed in non-agricultural activities; loans = Agricultural production units that received a loan, labour force $=$ Rural demographic dependency ratio

intermediate AC. Clusters with higher proportions of agricultural production units with secure land tenure also have higher proportions of land under basic grains. Most of these clusters have intermediate or lower AC. In El Salvador, the cluster (VI) with the highest proportion of agricultural production units with secure land tenure is also that with the highest proportion of land under coffee.

\section{Discussion}

Our study provides insights to guide adaptation implementation in four vulnerable Central American countries. We show, for example, that municipality clusters with lower basic needs satisfaction tend to underperform on indicators for innovation and action, suggesting adaptation actions focused on basic needs should receive high priority. We show that selecting indicators that underpin AC, like non-agricultural employment, instead of outcomes (e.g. child mortality) can also support prioritization for planned adaptation. Rural economically active population with non-agricultural employment was one of the most important factors defining AC clusters. Regional (Reardon et al. 2007) and country studies (Corral and Reardon 2001 in Nicaragua; Lanjouw 2001 in El Salvador; Ruben and Van Den Berg 2001 in Honduras) have shown that a good performance of this indicator contributes to poverty reduction among smallholders. Access to credit and technical assistance (associated with coffee farms) is related to intermediate $\mathrm{AC}$, because these factors do not guarantee opportunities for income diversification, highlighting that rural development policies emphasising agricultural incentives are not effective to promote territorial development (Reardon et al. 2007). Finally, distance to urban or more densely populated areas and higher non-farm employment have important effects on poverty (Plant 1998; Jamieson 1999), and our study highlights their relationship to AC. We found the rural demographic dependency ratio to be an important indicator of AC and potentially relevant to development interventions, as it is related to rural-urban migration or migration to other countries.

Evaluations of criteria and indicators to assess CCVA, as in our study, have previously been performed using both ranking and multivariate analysis for spatial comparative approaches (e.g. Nelson et al. 2009; Monterroso et al. 2014) with a high degree of consistency of results. We also found a high correlation (Spearman's $r$ correlation $>0.8$ ) between ACI and mean indicator values weighted by factor scores on PC1 (as suggested by Monterroso et al. 2014). Comparison between those two approaches to weighting indicators in terms of their effects on the ranking results is recommended. We used inputs from experts to estimate weights under the assumption that they reflect an overall view of the relative importance of different AC characteristics across the region. Further research should also focus on alternative 
standardization and weighting procedures to that used here to estimate $\mathrm{AC}$ and vulnerability indexes. The clustering analysis used here avoids some of these caveats by assuming that changes in indicator values are relevant to the characterization of $\mathrm{AC}$ and therefore depend on expert weighting of indicators. Our approach has regional scope and shows cluster-specific attributes that could define entry points for adaptation planning. However, we suggest that our results should be validated using local scale case studies (e.g. Sietz et al. 2011).

Although our results show high correlation between AC calculated using the ranking and cluster methods, we foresee different potential applications. Ranking can support prioritization of regions for interventions seeking improved $\mathrm{AC}$ and reduced vulnerability. Clustering can support the identification of regions requiring similar development strategies, for example, the improvement of basic needs satisfaction. Potential obstacles and opportunities can also be explored for regional strategies. For example, because of migration, labour availability may be insufficient for the implementation of novel farm practices in areas where current crops suitability will be lost.

Research priorities to improve CCVA at regional scales include, for PI assessment, integration of climate variability and non-climatic stresses and their interaction with climate change variables; and for AC assessment, the understanding and integration of indicators of social, cultural and political capitals, as well as the validation of AC distribution with existing local case studies and/or outcomes indicators. Governmental organizations or NGOs promoting local development could provide consistent information for this purpose.

Overall, our results regarding PI of climate change on current crop combinations are congruent with Schmidt et al. (2012) proposal of three future scenarios for Central American agriculture. The first scenario, pressure areas, is represented in our study by municipalities that are becoming more suitable for certain crops; the second scenario, adaptation areas, is represented in our study by those municipalities where current crop combinations are expected to remain viable with technological adjustments. Finally, the third scenario, hotspots, is represented in our study by municipalities where the expected suitability reduction is such that current crop combinations might not be economically feasible.

\section{Conclusions}

Projected changes in climate suitability for crops show a wide variation between Guatemala, El Salvador, Honduras and Nicaragua, and within each country. Results suggest that crops such as Gramineae (both C3 and C4 photosynthetic pathways) and roots will experience increases in average climatic suitability in all countries, but that others, like tree crops and beans, will experience decreases. Many of the gains occur in municipalities where suitability will increase for crops that are currently not a component of food-security (e.g. sorghum in the Caribbean basin), or in the highlands, where other land uses are currently a priority (e.g. protected areas). Both gains and losses of climatic suitability are therefore a challenge for adaptation.

A full spectrum of adaptation levels, as defined by Rickards and Howden 2012, must be considered in these four countries. In pressure areas and hotspots (respectively: areas that are becoming more suitable for certain crops, and areas where expected suitability reduction for current crop combinations may mean that current crop combinations become economically unfeasible), proposed adaptation pathways might require major and purposeful responses to climate change impacts and other drivers at the farm and supra-farm level (transformational adaptation). These adaptation strategies could include 
restoration of degraded lands, rearrangement of land uses across territories, livelihood diversification, and even migration. Where relatively low PI is expected - adaptation areas - changes in practices and technologies within current systems (incremental adaptation), that include adaptation strategies as changes of sowing dates or water harvest are recommended. Indeed, relatively small changes within the current systems (that include adaptation strategies as changes to drought resistant crops) might suffice. Current adaptive responses of small- and medium- scale agriculture in the region, like crop and income diversification, are well documented strategies of incremental and systems adaptation. This responses relies on land availability, cultural and social capital, and access to information, credits and subsidies (Magrin et al. 2014). Our results will help guide priorities for international cooperation as well as local agendas for the development of adaptation strategies based on expected impacts and gradients of AC. For example, where to focus on basic needs satisfaction to complement the development of adaptation strategies, or spatial prioritization for incremental or transformational adaptation.

Our approach can be applied in other countries or regions to identify spatial priorities for adaptation using widely-available data, though we suggest refinement of some aspects. Among these aspects (see, for example, Nelson et al. 2009 and Monterroso et al. 2014) are firstly, the estimation of PI in terms of changes in crop productivity related to climate variability (e.g. Schmidt et al. 2012), not just climatic suitability; secondly, the inclusion of social, cultural and natural assets in the characterization of the AC, and finally, a focus on agricultural landscapes rather than administrative divisions like municipalities.

We highlight the ranking method as a soundly-based, practical procedure for spatial prioritization of adaptation actions. However, given the different spatial patterns regarding of values of different indicators, cluster analysis is a valuable tool to define adaptation strategies for groups of municipalities. ACI and cluster analysis coincide in showing that current $\mathrm{AC}$ conditions form a gradient between municipalities where cash crops are grown, close to major urban areas; and municipalities where basic grains predominate at the agricultural frontier. The analysis of conditions for adaptation showed that municipalities with a higher basic needs satisfaction, generally also have high values of indicators regarding resources for innovation and action. This result confirms the coherence of our structure of criteria and indicators of AC conditions for showing development as a sequence of steps in adaptation processes.

Acknowledgments This work was co-funded by the CGIAR Research Program on Climate Change, Agriculture and Food Security (CCAFS) and the UNEP Regional Gateway for Technology Transfer and Climate Change Action in Latin America and the Caribbean (REGATTA). National workshops in Guatemala and Honduras were supported by the CASCADE project "Ecosystem-based Adaptation for Smallholder Subsistence and Coffee Farming Communities in Central America". Thanks to CASCADE project also for the invitation to attend the "Science Summit: Ecosystems, Climate Change and Smallholder Farmers in Central America" (May 12th-14th 2015, Punta Leona, Costa Rica), where we received valuable inputs from participants. This project is part of the International Climate Initiative (ICI); the German Federal Ministry for the Environment, Nature Conservation, Building and Nuclear Safety (BMUB) supports this initiative on the basis of a decision adopted by the German Bundestag. We also thank three anonymous reviewers for their constructive comments and The Betty and Gordon Moore Center for Science at Conservation International for providing funds for open access.

Open Access This article is distributed under the terms of the Creative Commons Attribution 4.0 International License (http:/creativecommons.org/licenses/by/4.0/), which permits unrestricted use, distribution, and reproduction in any medium, provided you give appropriate credit to the original author(s) and the source, provide a link to the Creative Commons license, and indicate if changes were made. 


\section{References}

Aguilar E, Peterson T, Ramírez-Obando P, et al. (2005) Changes in precipitation and temperature extremes in Central America and northern South America, 1961-2003. J Geophys Res. doi:10.1029/2005JD006119

Baca M, Läderach P, Haggar J, et al. (2014) An integrated framework for assessing vulnerability to climate change and developing adaptation strategies for coffee growing families in Mesoamerica. PloS One. doi:10. 1371/journal.pone.0088463

Bárcena A, Beteta HE, Lennox J (2011) La economía del cambio climático en Centroamérica. CEPAL, México

Bunn C, Läderach P, Ovalle-Rivera O, et al. (2015) A bitter cup: climate change profile of global production of Arabica and Robusta coffee. Clim Chang 129:89-101

CCAD (Central American Commission on Environment and Development) (2010) Estrategia regional de cambio climático. CCAD

Corbacho A, Davoodi H (2002) Expenditure issues and governance in Central America. IMF

Corral L, Reardon T (2001) Rural nonfarm incomes in Nicaragua. World Dev 29:427-442

Di Rienzo JA, Casanoves F, Balzarini, MG et al (2015) InfoStat version 2015. Grupo InfoStat, FCA, Universidad Nacional de Córdoba, Argentina. URLhttp://www.infostat.com.ar

Eakin H, Bojórquez-Tapia LA (2008) Insights into the composition of household vulnerability from multicriteria decision analysis. Global Environ Chang 18:112-127

Finegan B, Bouroncle C (2008) Patrones de la fragmentación de los bosques de tierras bajas, su impacto en las comunidades y especies vegetales y propuestas para su mitigación. In: Harvey CA, Sáenz JC (eds) Evaluación y conservación de la biodiversidad en paisajes fragmentados de Mesoamérica. INBio, Heredia, pp. 159-198

Flora CB (2004) Social aspects of small water systems. J Contemp Water Res Educ 128:6-12

Flora CB, Flora JL, Gasteyer SP (2015) Rural communities: legacy and change, 5th edn. Westview, Boulder

Ford JD, Keskitalo ECH, Smith T, et al. (2010) Case study and analogue methodologies in climate change vulnerability research. WIREs. Clim Chang 1:374-392

Giorgi F (2006) Climate change hot-spots. Geophys Res Lett. doi:10.1029/2006GL025734

Gourdji S, Läderach P, Martinez-Valle A, et al. (2015) Historical climate trends, deforestation, and maize and bean yields in Nicaragua. Agric For Meteorol 200:270-281

Hagerty MR (1999) Testing Maslow's hierarchy of needs: national Quality-of-Life across time. Social Indic Res 46:249-271

Harmeling S, Eckstein D (2012) Global climate risk index 2013. Who suffers most from extreme weather events? Weather-related loss events in 2011 and 1092 to 2012. Germanwatch, Bonn

Hijmans R, Guarino L, Cruz M, et al. (2001) Computer tools for spatial analysis of plant genetic resources data: 1. DIVA-GIS. Plant Genet Resour Newsl 127:15-19

Hijmans R, Cameron S, Parra J, et al. (2005) Very high resolution interpolated climate surfaces for global land areas. Int J Climatol 25:1965-1978

Imbach AC, Prado PF (2013) Assessing local adaptive capacity to climate change: conceptual framework and field validation. In: Ensor J, Huq S, Berger R (eds) Community-based adaptation to climate change: emerging lessons. Practical Action Publishing, Rugby, pp. 79-93

Imbach P, Molina LG, Locatelli B, et al. (2012) Modelling potential equilibrium states of vegetation and terrestrial water cycle of Mesoamerica under climate change scenarios. J Hydrometeorol 13:665-680

Imbach P, Beardsley M, Bouroncle C et al (2016) Climate-data based decision making for agriculture in Central America: state of the art from a multidisciplinary perspective. Climatic Change (submitted)

Jamieson M (1999) Poverty among the Indigenous Peoples of Nicaragua. Inter-American Development Bank

Knutsson P, Ostwald M (2006) A process-oriented sustainable livelihoods approach - a tool for increased understanding of vulnerability, adaptation, and resilience. Mitig Adapt Strateg Glob Chang. doi:10.1007/ s11027-006-4421-9

Kok K, Veldkamp A (2001) Evaluating impact of spatial scales on land use pattern analysis in central America. Agric Ecosyst Environ 85:205-221

Lanjouw P (2001) Nonfarm employment and poverty in rural El Salvador. World Dev 29:529-547

Locatelli B, Herawati H, Brockhaus M, et al. (2008) Methods and tools for assessing the vulnerability of forests and people to climate change: an introduction. CIFOR, Bogor

MAG (Ministry of Agriculture and Livestock, El Salvador) (2012) Estrategia ambiental de adaptación y mitigación al cambio climático del sector agropecuario, forestal y acuícola. MAG, San Salvador

MAGA (Ministry of Agriculture and Livestock, Guatemala) (2012) Plan Estratégico de Cambio Climático del Ministerio de Agricultura, Ganadería y Alimentación. MAGA, Guatemala City

MAGFOR (Ministry of Agriculture and Forestry, Nicaragua) (2013) Plan de adaptación a la variabilidad y el cambio climático en el sector agropecuario, forestal y pesca en Nicaragua. MAGFOR, Managua 
Magrin GO, Marengo JA, Boulanger J-P, et al. (2014) Central and South America. In: Field CB, Barros VR, Dokken DJ, et al. (eds) Climate Change 2014: Impacts, Adaptation, Vulnerability. Part B: Regional Aspects. Contribution of Working Group II to the Fifth Assessment Report of the IPCC. Cambridge University Press, Cambridge, pp. 1499-1566

Malczewski J (1999) GIS and multicriteria decision analysis. Wiley, New York, pp. 177-195

Malone EL, Engle NL (2011) Evaluating regional vulnerability to climate change: purposes and methods. WIREs. Clim Chang 2:462-474

Metternicht G, Sabelli A, Spensley J (2014) Climate change vulnerability, impact and adaptation assessment. Int J Clim Chang Strateg Manag 6:442-476

Monterroso A, Conde C, Gay C (2014) Two methods to assess vulnerability to climate change in the Mexican agricultural sector. Mitig Adapt Strateg Glob Chang 19:445-461

Nelson R, Kokic P, Crimp S, et al. (2009) The vulnerability of Australian rural communities to climate variability and change: part II-integrating impacts with adaptive capacity. Environ Sci Pol 13:18-27

Ovalle-Rivera O, Läderach P, Bunn C, et al. (2015) Projected shifts in Coffea arabica suitability among major global producing regions due to climate change. PLoS One 10:e124155

Parry M, Canziani OF, Palutikof J et al (2007) Climate Change 2007: Impacts, Adaptation and Vulnerability. Contribution of Working Group II to the Fourth Assessment Report of the IPCC. Cambridge University Press, Cambridge

Plant R (1998) Indigenous Peoples and Poverty Reduction: A Case Study of Guatemala. Inter-American Development Bank

Rahn E, Läderach P, Baca M, et al. (2014) Climate change adaptation, mitigation and livelihood benefits in coffee production: where are the synergies? Mitig Adapt Strateg Glob Chang 19:1119-1137

Ramírez-Villegas J, Jarvis A (2010) Downscaling Global Circulation Model outputs: the Delta method decision and Policy analysis. CIAT, Cali

Rauscher SA, Giorgi F, Diffenbaugh NS, et al. (2008) Extension and intensification of the Meso-American midsummer drought in the twenty-first century. Clim Dyn 31:551-571

Reardon T, Stamoulis K, Pingali P (2007) Rural nonfarm employment in developing countries in an era of globalization. Agric Econ 37:173-184

Rickards L, Howden SM (2012) Transformational adaptation: agriculture and climate change. Crop Pasture Sci 63:240-250

Ruben R, Van Den Berg M (2001) Nonfarm employment and poverty alleviation of rural farm households in Honduras. World Dev 29:549-560

SAG (Secretariat of Agriculture and Livestock, Honduras) (2010) Estrategia del Sector Público Agroalimentario y Plan de Implementación. SAG, Tegucigalpa

Schmidt A, Eitzinger A, Sonder K et al (2012) Tortillas on the roaster: Central American maize-bean systems and the changing climate. CRS, CIAT, CIMMYT. doi:10.13140/RG.2.1.4853.9044

Scoones I (2009) Livelihoods perspectives and rural development. J Peasant Studies 36:171-196

SICA (Central American Integration System) (2008) Estrategia regional agroambiental y de salud de Centroamérica. SICA

Siegel PB (2005) Using an asset-based approach to identify drivers of sustainable rural growth and poverty reduction in Central America: A conceptual framework. The World Bank, Washington DC

Sietz D, Lüdeke MKB, Walther C (2011) Categorisation of typical vulnerability patterns in global drylands. Global Environ Chang 21:431-440

Sietz D, Mamani-Choque SE, Lüdeke MKB (2012) Typical patterns of smallholder vulnerability to weather extremes with regard to food security in the Peruvian Altiplano. Reg Environ Chang 12:489-505

Stillwell WG, Seaver DA, Edwards W (1981) A comparison of weight approximation techniques in multiattribute utility decision making. Organ Behav Hum Perf 28:62-77

Tonmoy FN, El-Zein A, Hinkel J (2014) Assessment of vulnerability to climate change using indicators: a metaanalysis of the literature. WIREs. Clim Chang 5:775-792

Tucker CM, Eakin H, Castellanos EJ (2010) Perceptions of risk and adaptation: coffee producers, market shocks, and extreme weather in central America and Mexico. Global Environ Chang 20:23-32

UNDP (2014) Human Development Report 2014. UNDP, New York 